\title{
AN INVESTIGATION OF THE ROLE OF WATER ON RETROGRADE/CONDENSATION REACTIONS AND ENHANCED LIQUEFACTION YIELDS
}

\author{
DISCLAIMER
}

by

Franci $\cdot$ P. Miknis

April 1993
This report was prepared as an account of work sponsored by an agency of the United States Government. Neither the United States Government nor any agency thereof, nor any of their employees, makes any warranty, express or implied, or assumes any legal liability or responsibility for the accuracy, completeness, or usefulness of any information, apparatus, product, or process disclosed, or represents that its use would not infringe privately owned rights. Reference herein to any specific commercial product, process, or service by trade name, trademark, manufacturer, or otherwise does not necessarily const ute or imply its endorsement, recommendation, or favoring by the United States Government or any agency thereof. The views and opinions of authors expressed herein do not necessarily state or reflect those of the United States Government or any agency thereof.

Quarterly Progress Report: January 1, 1993 - March 31, 1993

Work Performed Under DOE Contract DE-AC22-91PC91043

For

U.S. Department of Energy

Pittsburgh Energy Technology Center

P.O. Box 10940

Pittsburgh, PA 15236-0940

By

Western Research Institute

a.k.a. Western Research Institute

Laramie, Wyoming
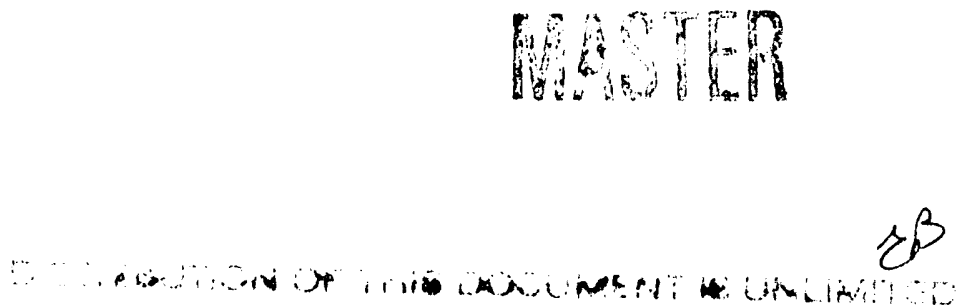


\section{TABLE OF CONTENTS}

Page

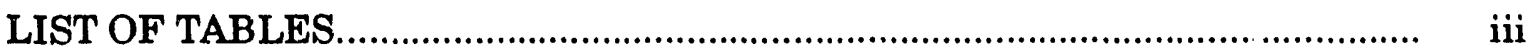

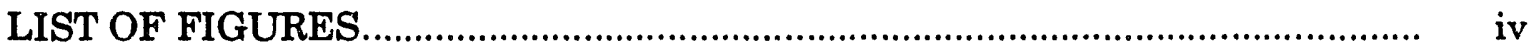

BACKGROUND

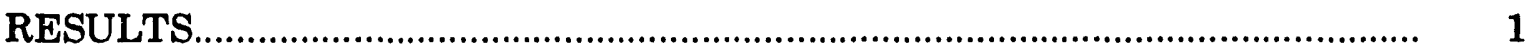

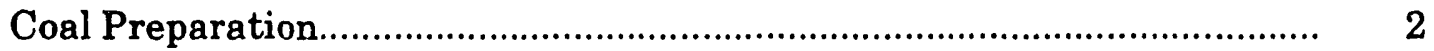

Thermal Drying....................................................................................... 2

Microwave Drying........................................................................................ 3

Chemical Drying................................................................................. 5

Coal Liquefaction Experiments.............................................................. $\quad 7$

FUTURE WORK

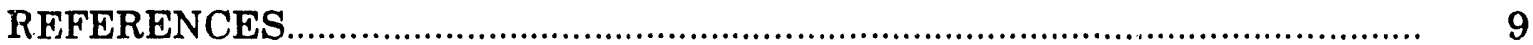




\section{LIST OF TABLES}

\section{Table}

Page

1. Proximate and Ultimate Analyses of Coals........................................... 10

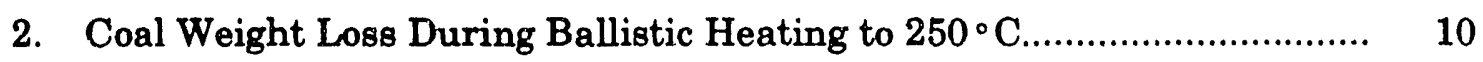




\section{LIST OF FIGURES}

Figure

Page

1. Solid-state ${ }^{13} \mathrm{C}$ NMR spectra of Eagle Butte coal ballistically heated to $250^{\circ} \mathrm{C}$.

2. Microwave calibration curve.................................................................

3. Microwave drying curve for Texas coal........................................................ 13

4. Microwave drying curve for Black Thunder coal........................................ 14

5. Microwave drying curve for Illinois No. 6 coal........................................... 15

6. Microwave drying curve for coals............................................................... 16

7. Microwave drying curve for Linde 13X molecular sieve............................. 17

8. Solid-state ${ }^{13} \mathrm{C}$ NMR spectra of microwave-dried Texas coal....................... 18

9. Proton NMR spectrum of dimethoxypropane, acetone, and cycloheptane standard....................................................................... 19

10. Plot of moisture determined by chemical drying vs. moisture determined thermally

11. Water content of coals determined by isotopic dilution vs. moisture determined by ASTM 3173

12. Temperature profiles in coal liquefaction reactor.

13. Comparison of coal liquefaction conversion for "moisturized" and dried Eagle Butte coal.

14. Solid-state ${ }^{13} \mathrm{C}$ NMR spectra of THF insoluble residues from liquefaction experiments on thermally and chemically dried Eagle Butte coal. 


\section{BACKGROUND}

The overall objectives of this work are to conduct research that will provide the basis for an improved liquefaction process, and to facilitate our understanding of those processes that occur when coals are initially dissolved. Changes in coal structure that may occur during coal drying will be measured in order to determine the effects of coal drying on its reactivity toward liquefaction. Different methods for coal drying will be investigated to determine if drying can be accomplished without destroying coal reactivity toward liquefaction, thereby making coal drying a relatively economical and efficient method for coal pretreatment. Coal drying methods will include conventional thermal drying, microwave drying, and chemical drying at low temperature. State-of-the-art solid-state nuclear magnetic resonance (NMR) techniques using combined rotation and multiple pulse spectroscopy (CRAMPS) and cross polarization with magic-angle spinning (CP/MAS) will be employed: (1) to measures changes in coal structure brought about by the different methods of drying and by low temperature oxidation, and (2) to obtain direct measurements of changes in the aromatic hydrogen-to-carbon ratio of the solid/semisolid material formed or remaining during pretreatment and the initial stages of liquefaction. The aromatic hydrogen-to-carbon ratios are difficult, if not impossible, to measure without the use of solid-state NMR.

\section{RESULTS}

The objectives for this quarter were to begin coal drying experiments using thermal, microwave, and chemical methods, and to begin coal liquefaction experiments on the dried coals. Three additional coal samples have been acquired. These are a Black Thunder Mine coal acquired from Arco Coal Co, and a Texas subC and Illinois No. 6 hvC acquired from the DOE coal sample bank at Penn State. The samples are listed as DECS-1 and DECS-2, respectively in the PSU sample bank. The ultimate and proximate analyses for all the samples are given in Table 1 . Work on each of the subtasks is described in separate paragraphs. 


\section{Coal Preparation}

Master batch samples $(\sim 500 \mathrm{~g})$ of coals were prepared by grinding and screening to $-20,+100$ mesh particle size. The samples were placed in a wide mouth jar and placed in an oven with a beaker of water, and allowed to equilibrate at $40^{\circ} \mathrm{C}$ for 24 hrs. The samples were then removed from the oven and placed in a humidifier until aliquots were taken for the different drying and liquefaction tests.

\section{Thermal Drying}

Samples of the four coals were heated to different final temperatures in order to determine at what temperature significant structural changes begin to occur that might affect the liquefaction behavior. These heating experiments are referred to as ballistic heating experiments. The ballistic heating experiments were performed with a small, vertically aligned furnace. The furnace has a 12 -centimeter long heated section which accepts a 1.4-centimeter i.d. quartz liner. A stainless steel screen provides support for the coal and a steel wool pack heats the nitrogen sweep gas which is introduced at the bottom of the quartz liner. In a typical experiment, the furnace is preheated to about $10^{\circ} \mathrm{C}$ above the desired final coal temperature. A 2 -gram coal sample is then poured into the quartz liner and a thermocouple is inserted into the coal sample bed. When this thermocouple reaches the desired temperature, the quartz liner is removed from the furnace and allowed to cool. Nitrogen flow is maintained at all times. When the sample temperature is below $50^{\circ} \mathrm{C}$ the coal is poured into a sample vial, capped with nitrogen, and sealed. Heatup times with this system are typically from 15 to 20 minutes.

In the previous quarter, we reported that samples of Eagle Butte coal, ballistically heated to final temperatures of $100,150,200$, and $250^{\circ} \mathrm{C}$, did not show any dramatic changes in carbon structure. Ballistic heating experiments to a temperature of $250^{\circ} \mathrm{C}$ have been conducted on the Black Thunder, Texas and Illinois 
No.6 coal samples. The weight losses and moisture values of the coals are given in Table 2.

Solid-state ${ }^{13} \mathrm{C}$ NMR measurements were made on the samples heated to $250^{\circ} \mathrm{C}$. Overall, there were not any dramatic changes in the carbon structure as a result of ballistic heating to $250^{\circ} \mathrm{C}$. The most noticeable change in the NMR spectra is in the carboxyl region ( $180 \mathrm{ppm})$, where there is evidence of some decarboxylation having taken place during heating. There are also some slight changes in the aliphatic region (0-60 ppm). In particular there is some narrowing of the aliphatic band in the spectrum of the heated coal. An example is shown in Figure 1 for the Eagle Butte coal. These results are also in agreement with the data in Table 2 which shows that the weight losses after heating are greater than the moisture content of the unheated coals.

\section{Microwave Drying}

Microwave drying is an alternative thermal method of drying coals. However, the mechanism of drying with microwaves is different from that of simply heating the coal. In order for a substance to absorb microwaves and become heated, it must have a permanent dipole moment. Therefore, the functional groups that are the most efficient absorbers of microwaves are those that are highly polar, such as the $-\mathrm{OH}$ group in water.

When a substance containing water molecules is exposed to microwaves of the proper frequency $(2,450 \mathrm{MHz})$ the water molecules attempt to align and realign with the alternating electric field of the microwaves. This causes friction at the molecular level, which becomes manifested as heat. Because the water in coals can be distributed on the surface, in pores, or as part of the coal structure as in a gel, depending on rank, microwaves might be used to provide some selectivity for coal drying without appreciably affecting the overall coal structure and liquefaction behavior of the coal. 
The objective of the microwave drying subtask is to determine whether microwave drying alters the structure and composition of the coal, and hence its behavinr toward liquefaction. This work was prompted by earlier work of Silver et al. $(1,2)$ that showed that drying coal with microwaves beyond $\sim 75 \%$ moisture removal actually had a detrimental effect on the reactivity toward liquefaction. However, there has not been a systematic study of changes in coal structure induced by microwave drying.

Microwave drying experiments were conducted on several coals during the quarter. These experiments were conducted in the following manner: $\sim 2$ grams of coal were placed in $25 \mathrm{~mL}$ beakers, and the beakers placed at the center of the microwave oven. Samples were exposed to microwave radiation for different periods of time and at different power levels, after which the samples were removed from the oven and a thermocouple inserted into the coal bed to determine an average temperature.

At full power ( 600 watts), $75 \%$ or greater of the moisture was removed in $\sim 2$ min., and removal of the remaining moisture caused the temperatures to increase rapidly. Because of the rapid moisture removal at full power, different levels of microwave power were used in order to obtain a more complete drying curve. At power levels of 300 watts, $25-75 \%$ moisture could be removed for irradiation times of up to $15 \mathrm{~min}$. A calibration curve for calculated microwave power and the power settings on the microwave oven is shown in Figure 2.

The microwave drying curves for the Texas, Black Thunder and Illinois No.6 coals are shown in Figures 3-5. In all cases the coals show a similar microwave drying behavior, in that the temperature remains at approximately the boiling point of water until $\sim 80 \%$ of the moisture is removed. After that, there is a rapid rise in temperature during removal of the remaining moisture. A "master" microwave drying curve that includes data from microwave drying experiments on all types of coals, including Beulah North Dakota lignite and Utah Blind Canyon bituminous coal, is shown in Figure 6. 
The moisture that comes off at the higher temperature could be due to water in different pores, or could be due to water that is an integral part of the gel structure of the coals. To test these ideas, a microwave drying curve was also measured for a Linde $13 \mathrm{X}$ molecular sieve containing $30.56 \%$ moisture. The microwave drying curve for the molecular sieve (Figure 7.) is similar to the ones for the coals, especially the low rank coals. Based on the results for the molecular sieve, we conclude that the microwave drying curves reflect mostly the drying behavior of the water in different sized pores, and are not caused by changes in the carbon structure of the coals.

This interpretation is supported by the solid-state ${ }^{13} \mathrm{C}$ NMR measurements of the microwave dried coals, which show little changes in carbon structure between the original coal and its microwave-dried counterpart. However, the Texas coal appeared to be an exception in that some aromatic carbon relative to the aliphatic carbon (Figure 8). Also, the shoulder due to phenolic carbons ( 155 ppm) is less resolved in the spectrum of the microwave-dried sample. Additional experiments will be performed during the next quarter to determine whether this effect is real.

\section{Chemical Drying}

Chemical drying of coals is a relatively unexplored technique for removing water at low temperature. Thermal methods of drying can alter the physical structure of coal as well as promote undesirable chemical reactions. Low-temperature drying of coal, on the other hand, should preserve the structural integrity, reduce retrograde reactions, reduce thermal degradation, and provide information on nonbonded, chemisorbed, and physisorbed water.

Pore water and surface adsorbed water on coal can be effectively removed by the use of a chemical dehydration agent, 2,2-dimethoxypropane (DMP). The reaction of DMP with water is, 


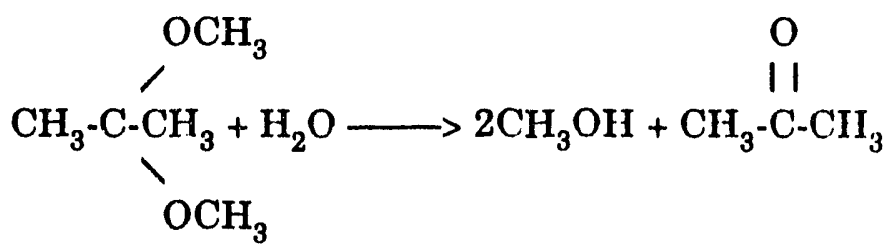

This reaction is rapid ( $<10 \mathrm{~min}$ ) and endothermic. The use of DMP to dehydrate coal accomplishes two things: (1) the removal of water at ambient temperature by chemical means rather than by physically forcing exchange by mass action preserves the structural integrity of the coal components and (2) the reaction products can easily be measured quantitatively to determine the amount of water in coal.

Chemical drying experiments were conducted on the coals during the quarter using 2,2-dimethoxypropane (DMP) as a drying agent. One-half gram of coal was weighed into a $10 \mathrm{~mL}$ centrifuge tube followed by $1 \mathrm{~mL}$ of $0.2 \mathrm{~N} \mathrm{CH}_{3} \mathrm{SO}_{3} \mathrm{H}$ in $\mathrm{CH}_{3} \mathrm{OH}$ and 0.7 $\mathrm{mL}$ of the reference standard cycloheptane. Two $\mathrm{mL}$ of dimethoxypropane were then added to the mixture. The total mixture was stirred, and after 16 hours, a one-half $\mathrm{mL}$ aliquot was removed, diluted with one-half $\mathrm{mL} \mathrm{CDCl}{ }_{3}$, and the ${ }^{1} \mathrm{H} \mathrm{NMR}$ spectrum recorded. The solution was stirred and centrifuged prior to removing the aliquots.

$\mathrm{A}^{1} \mathrm{H}$ NMR method was developed to rapidly measure the amount of water in coal produced by the reaction of DMP with the water in coal. The ${ }^{1} \mathrm{H}$ NMR spectra of the reaction products, methanol and acetone, give single resonances for the methyl groups, which are easily identified (Figure 9). These resonances do not overlap the hydrogen NMR resonances of DMP. Integration of the methyl resonances from acetone is used to measure directly the moles of water reacted. The average relative error using the ${ }^{1} \mathrm{H}$ NMR method is < $3 \%$ for standard solutions with a known amount of water. A curve-fitting routine for determining the area of the peaks increases the precision and accuracy of the NMR method by eliminating instrumental and other artifacts which contribute to the peak shape.

The results of the initial chemical drying experiments are summarized in Figure 10. Two of the coals, Beulah North Dakota lignite and Blind Canyon bituminous, are 
being investigated under DOE grant, DE-FG22-91PC91310. The average moisture content measured with DMP appears to he higher than that measured thermally in which the weight loss is measured at $105^{\circ} \mathrm{C}$. These results indicate that the chemical drying method removes more moisture from the coal than does the ASTM drying procedure. Presumably, the additional water is due to water that is more tightly bound in pores that is not liberated at $105^{\circ} \mathrm{C}$. Finseth (3) also observed a greater moisture removal from different coals using an isotopic dilution method (Figure 11). It is interesting that the additional water measured by Finseth's isotopic dilution method and the chemical drying method appear to be $\sim 10 \%$ greater than that obtained by thermal drying.

\section{Coal Liquefaction Experiments}

Coal liquefaction experiments were conducted during the quarter on the Eagle Butte subbituminous coal using the stirred microautoclave apparatus. These experiments were conducted using a 1:1 weight ratio of coal to tetralin. The initial coal sample had a weight of $20 \mathrm{~g}$ and was screened to a $-20+100 \mathrm{mesh}$ particle size. The autoclave was pressurized with hydrogen at 900 psig. Liquefaction experiments were conducted at $425{ }^{\circ} \mathrm{C}$ for a period of 30 minutes. Typical temperature profiles for the sand bath, coal slurry, and vapor are shown in Figure 12.

The coal liquefaction experiments conducted on Eagle Butte are summarized in Figure 13. The original coal, containing $\sim 20 \%$ moisture, had a conversion of $\sim 85 \%$, based on extracting the coal residue with THF. The liquefaction conversions of Eagle Butte that were dried by ballistic heating (thermal), microwaves, or chemical drying are substantially lower. These results agree with other results that have reported reduced liquefaction conversions for "completely" dried coals. Experiments are planned for next quarter in which the liquefaction behavior of partially dried coals will be determined.

CP/MAS ${ }^{13} \mathrm{C}$ NMR spectra of the thermally and chemically dried coal liquefaction residues are shown in Figure 14. The spectrum for the microwave dried residue is 
similar. The residue here is the material remaining after THF extraction. In all cases, when compared to the starting coal spectrum, the NMR spectra of the residues show a significant reduction in the aliphatic component relative to the aromatic component. In addition there is a substantial narrowing of the aromatic resonance band as carbons substituted on aromatic rings $(\sim 140 \mathrm{ppm})$, phenolic $(\sim 155$ ppm) and carboxylate carbons $(\sim 180 \mathrm{ppm})$ evolve as liquid products during conversion.

There is also a shift in the resonance position from $\sim 30 \mathrm{ppm}$ to $\sim 20 \mathrm{ppm}$ for the aliphatic carbons. The residual aliphatic component at $\sim 20 \mathrm{ppm}$ could be due to methyl groups attached to aromatic rings that would not be cleaved during liquefaction at $425^{\circ} \mathrm{C}$.

\section{FUTURE WORK}

Next quarter work will focus on: (1) performing liquefaction experiments on partially dried coals, (2) obtaining liquid-state NMR measurements and elemental analyses on the products, and (3) initiating combined rotation and multiple pulse spectroscopy (CRAMPS) ${ }^{1} \mathrm{H}$ NMR measurements on the moisturized and dried coals. 
REFERENCES

1. Silver H.F., W.S. Frazee, Integrated Two-Stage Coal Liquefaction Studies, University of Wyoming, Laramie, WY, August 1985, EPRI report AP-4193, 460 p.

2. Silver H., P.J. Hallinan, W.S. Frazee, Amer. Chem. Soc. Div. Petrol. Chem. Preprints, 1986, 31(3),755.

3. Finseth, D., 1987, ACS Div. Fuel Chem. preprints, 32(4): 260-265. 
Table 1. Proximate and Ultimate Analyses of Coals

\begin{tabular}{lcccc}
\hline & $\begin{array}{c}\text { Eagle } \\
\text { Butte }\end{array}$ & $\begin{array}{c}\text { Black } \\
\text { Thunder }\end{array}$ & Texas & $\begin{array}{c}\text { Illinois } \\
\text { No. } 6\end{array}$ \\
& & & & \\
Proximate Analysis, \% as rec'd & & & & \\
Moisture & & & & \\
Ash & 29.2 & 27.9 & 30.0 & 10.4 \\
Volatile Matter & 4.7 & 4.7 & 11.1 & 14.5 \\
Fixed Carbon & 30.9 & 32.0 & 33.2 & 34.2 \\
& 35.2 & 35.5 & 25.8 & 40.9 \\
Ultimate Analysis, \% dry & & & & \\
Ash & & & & \\
Carbon & 6.6 & 6.2 & 15.8 & 16.2 \\
Hydrogen & 67.4 & 68.5 & 62.5 & 65.5 \\
Nitrogen & 5.1 & 3.9 & 4.8 & 4.6 \\
Total Sulfur & 0.9 & 0.5 & 1.2 & 1.1 \\
Oxygen (difference) & 0.6 & 0.5 & 1.0 & 4.5 \\
& 19.4 & 20.4 & 14.7 & 8.2 \\
\hline
\end{tabular}

Table 2. Coal Weight Loss During Ballistic Heating to $250^{\circ} \mathrm{C}$

\begin{tabular}{ccc}
\hline Coal & \% Moisture & \% Weight Loss \\
\hline Texas, DECS-1 & 28.73 & 26.88 \\
Ill. No. 6, DECS-2 & 9.79 & 11.63 \\
Eagle Butte & 18.54 & 19.81 \\
Black Thunder & 23.22 & 24.02 \\
\hline
\end{tabular}




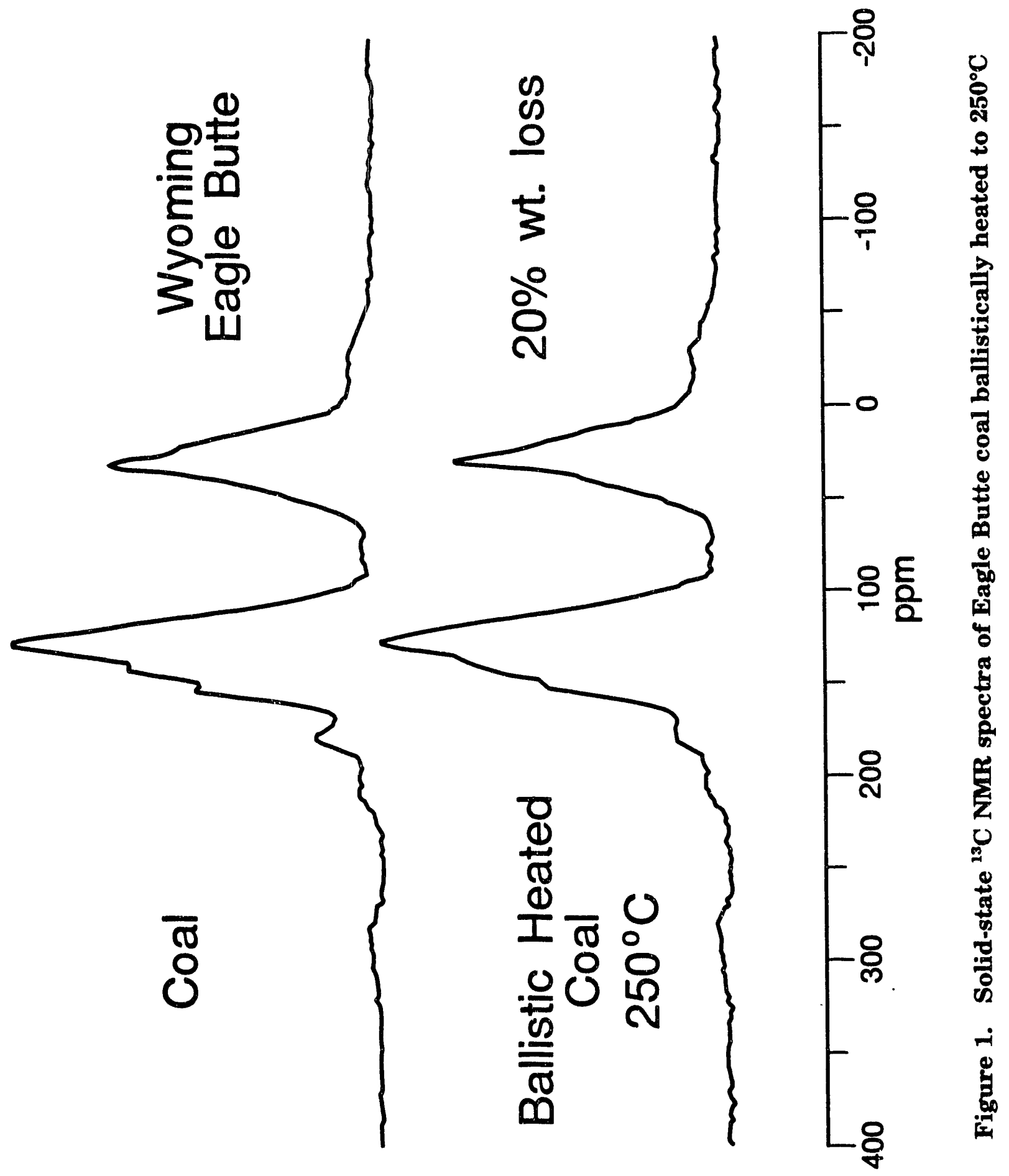




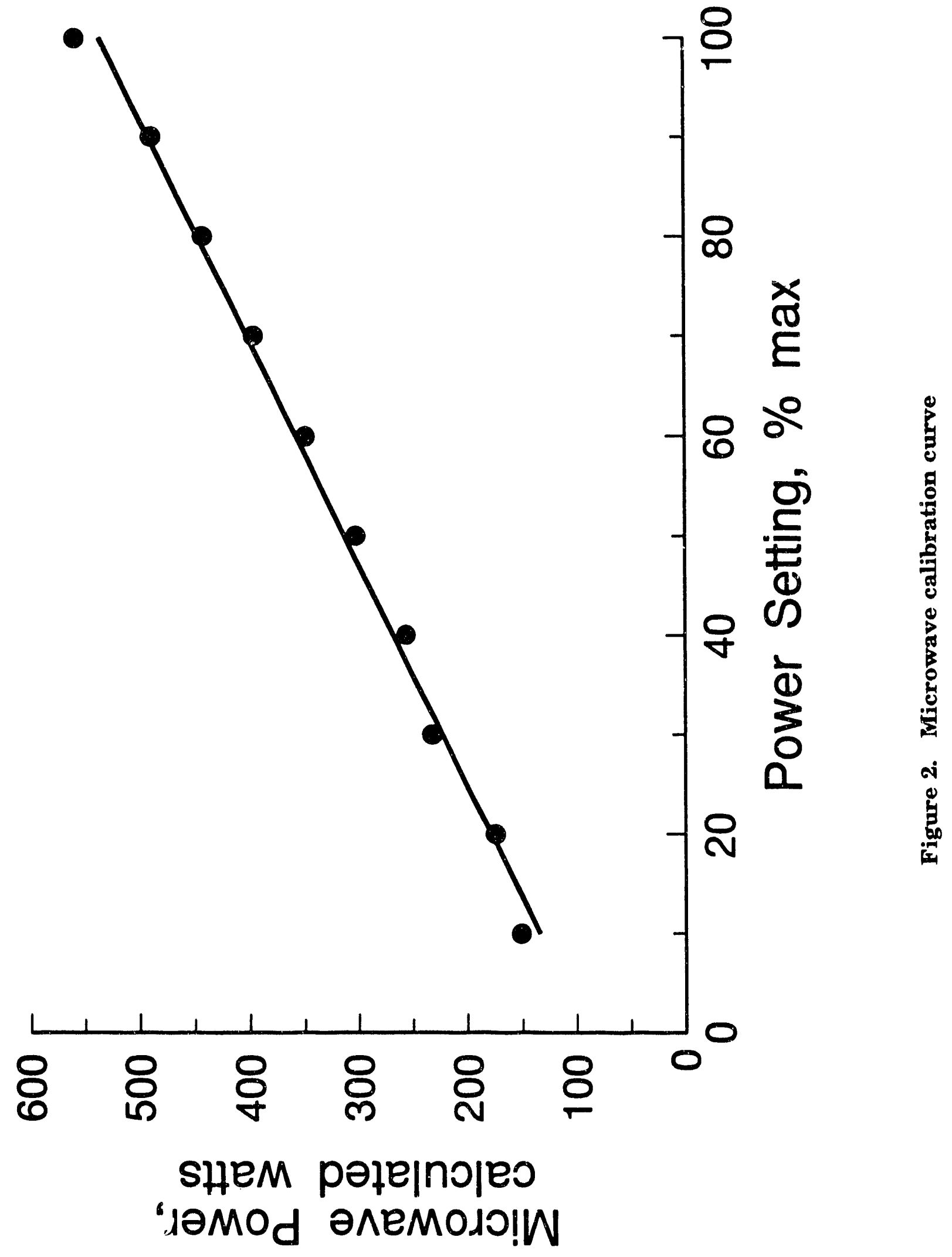




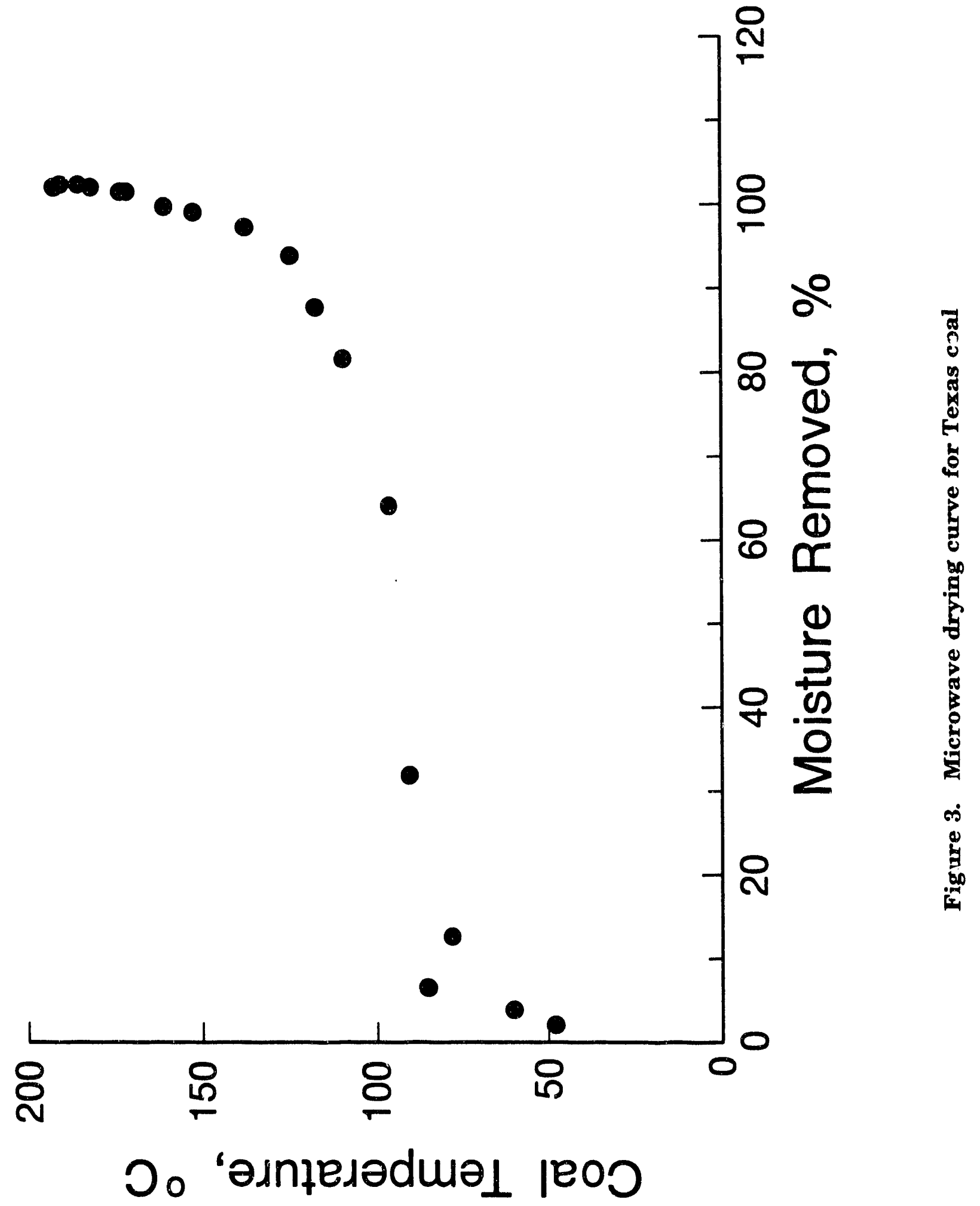




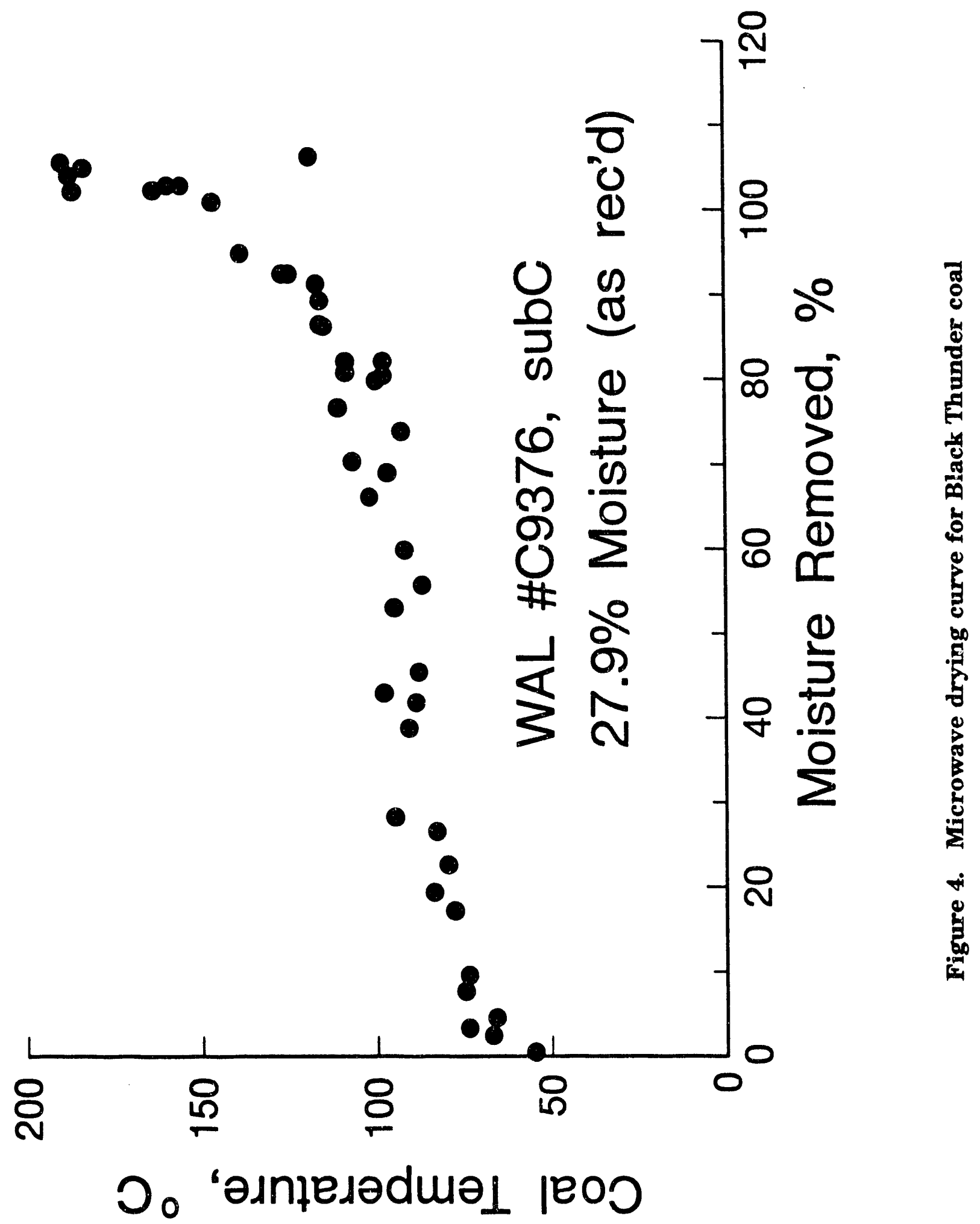




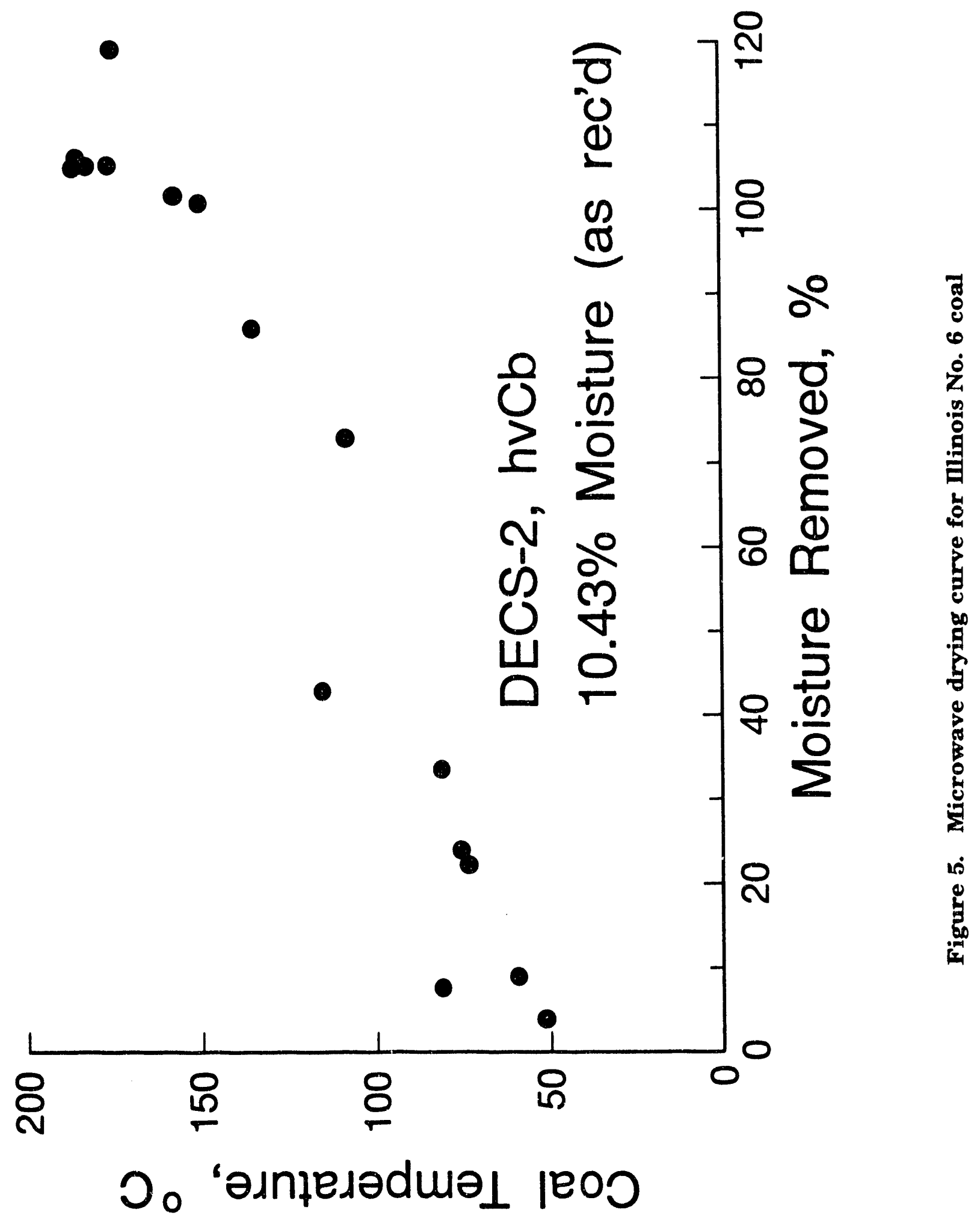




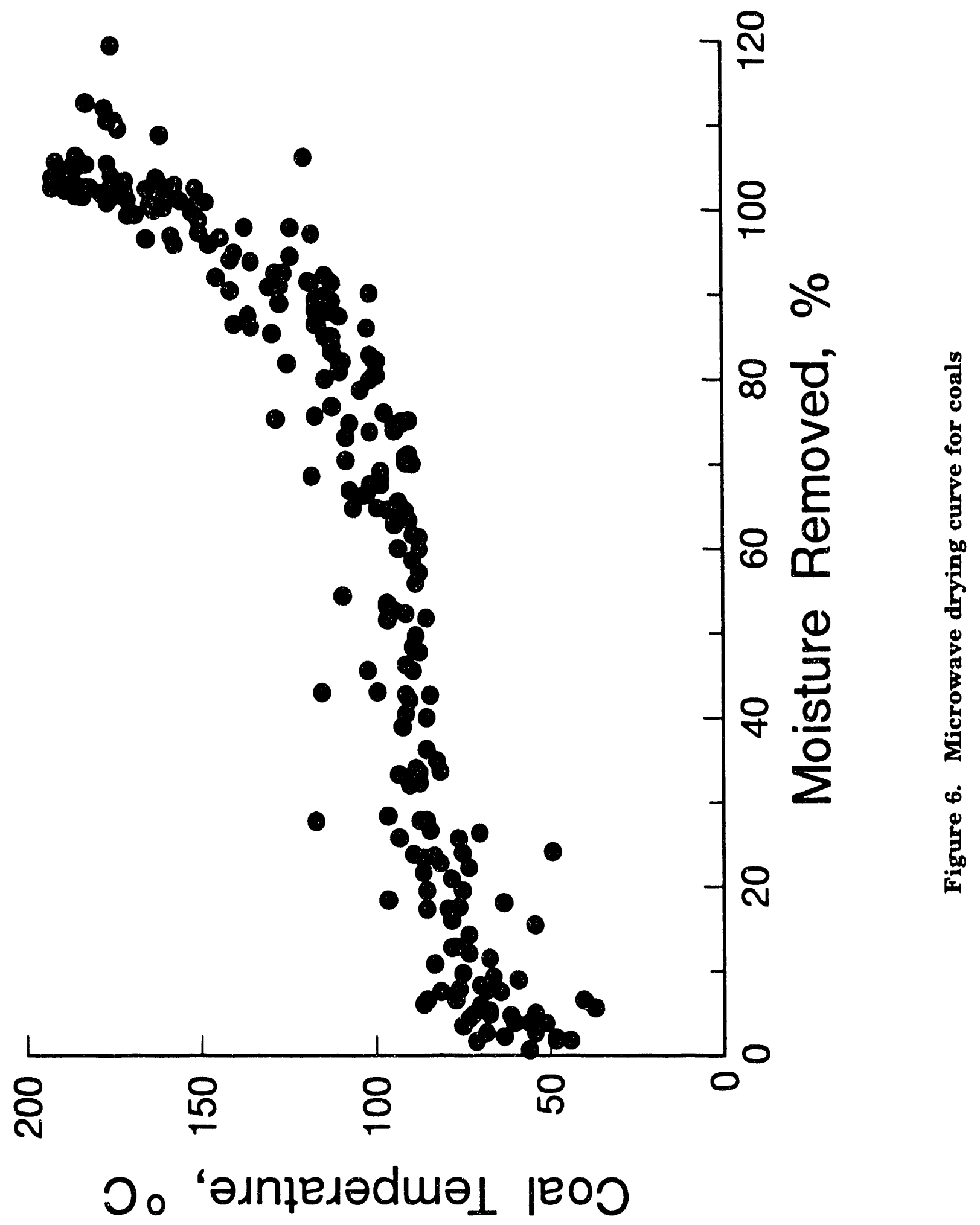




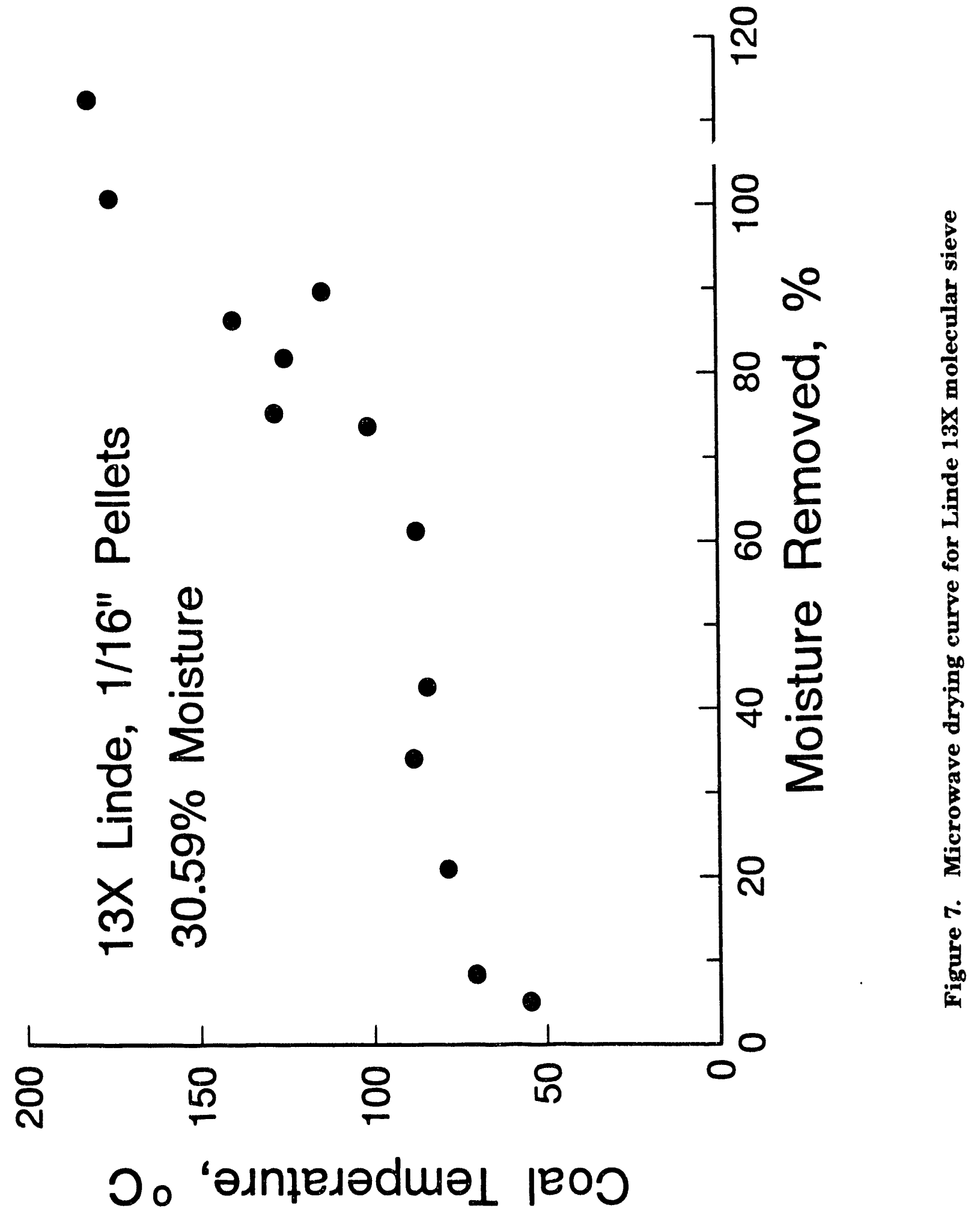




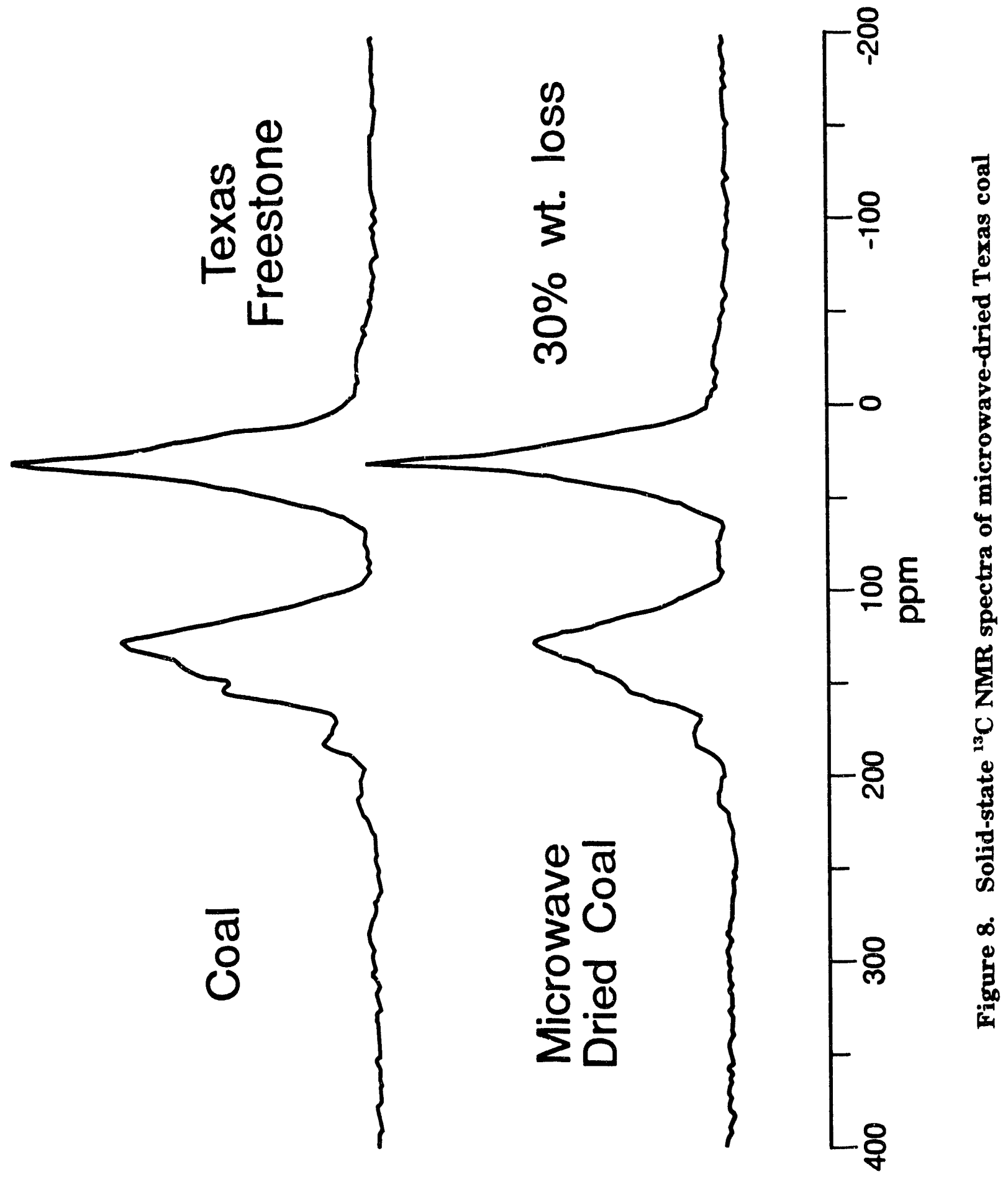




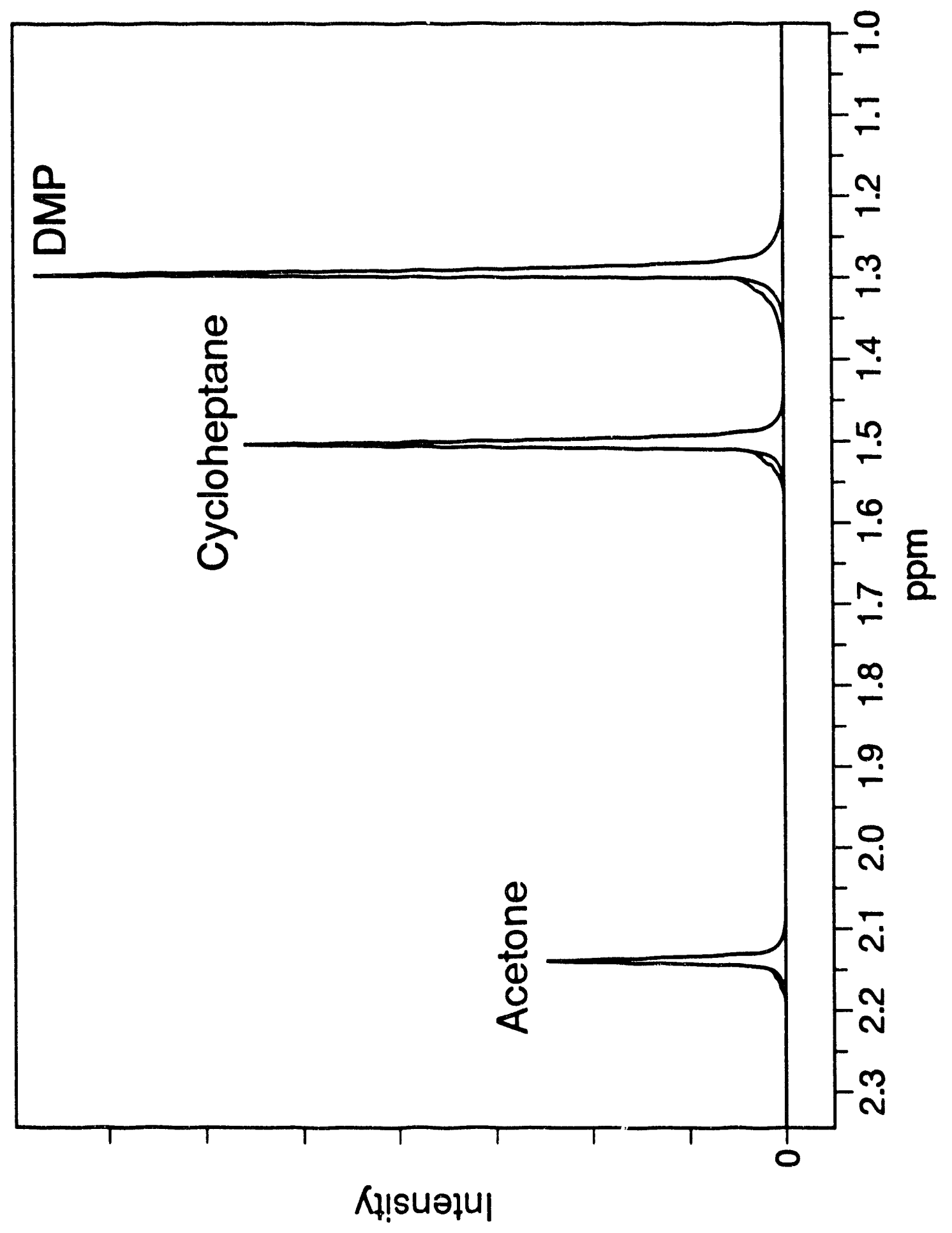

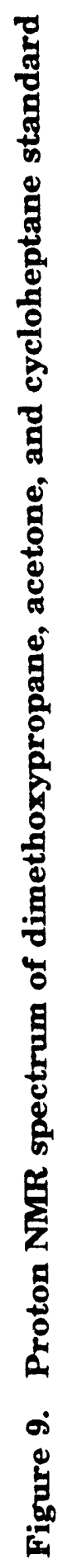




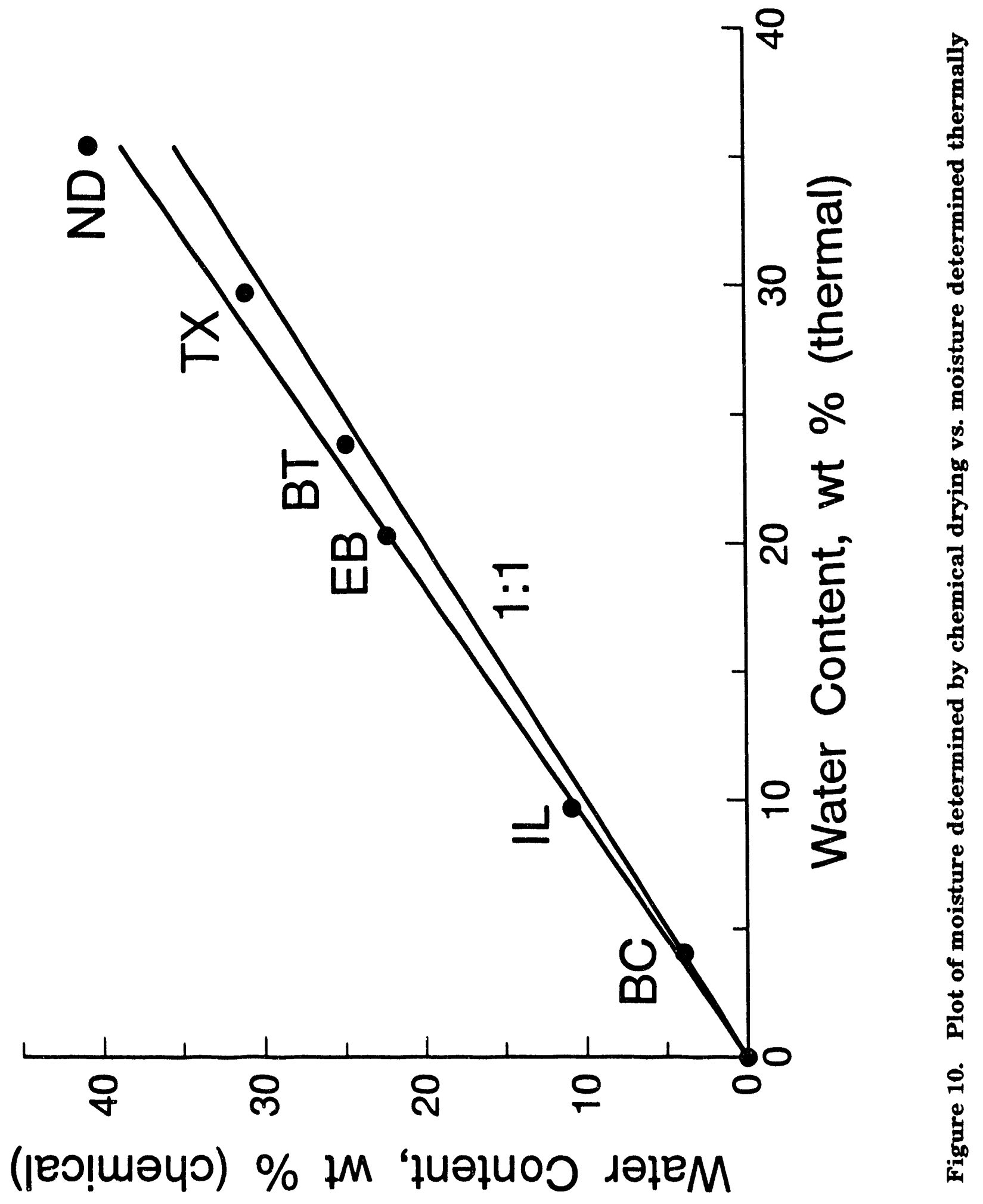




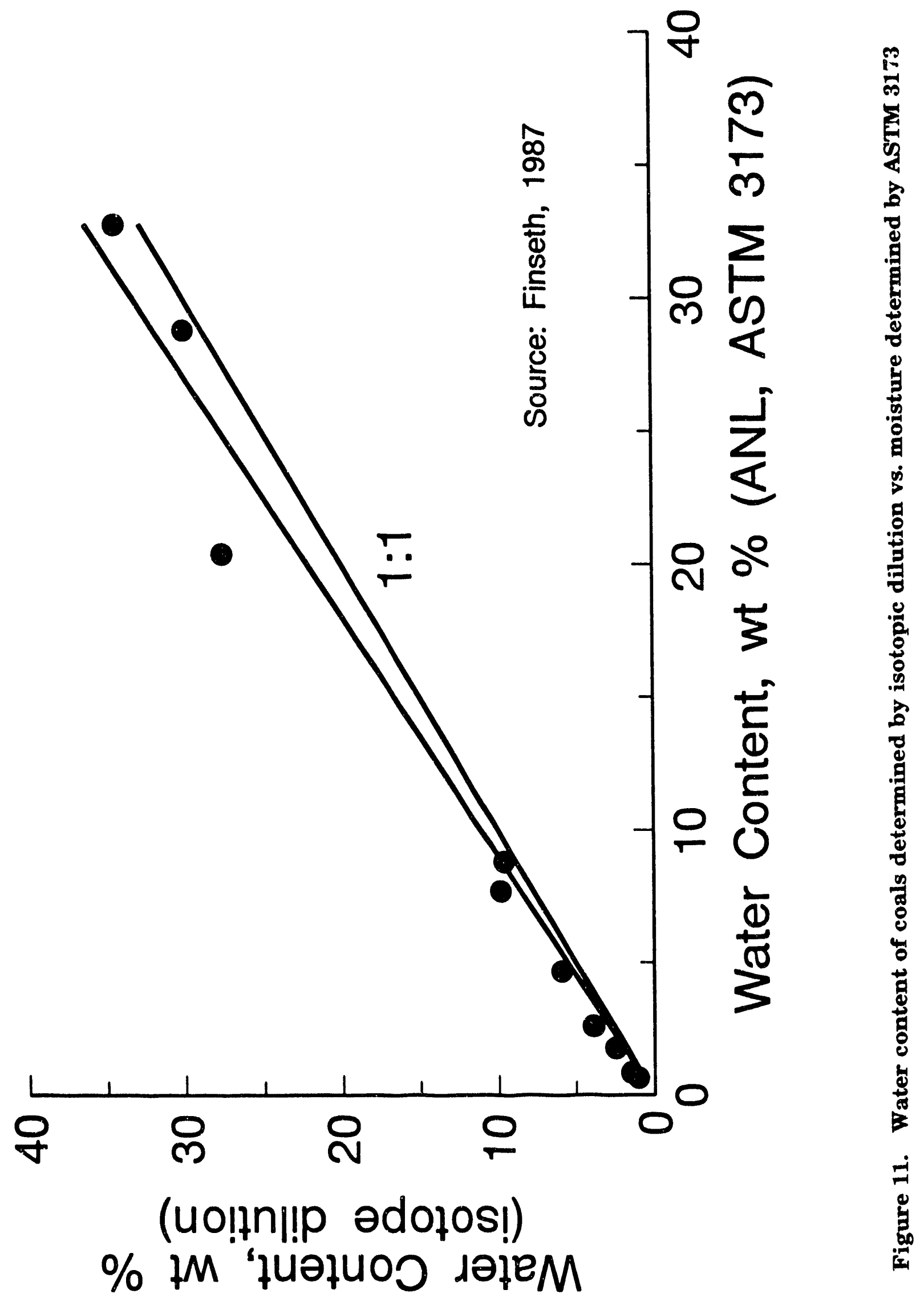




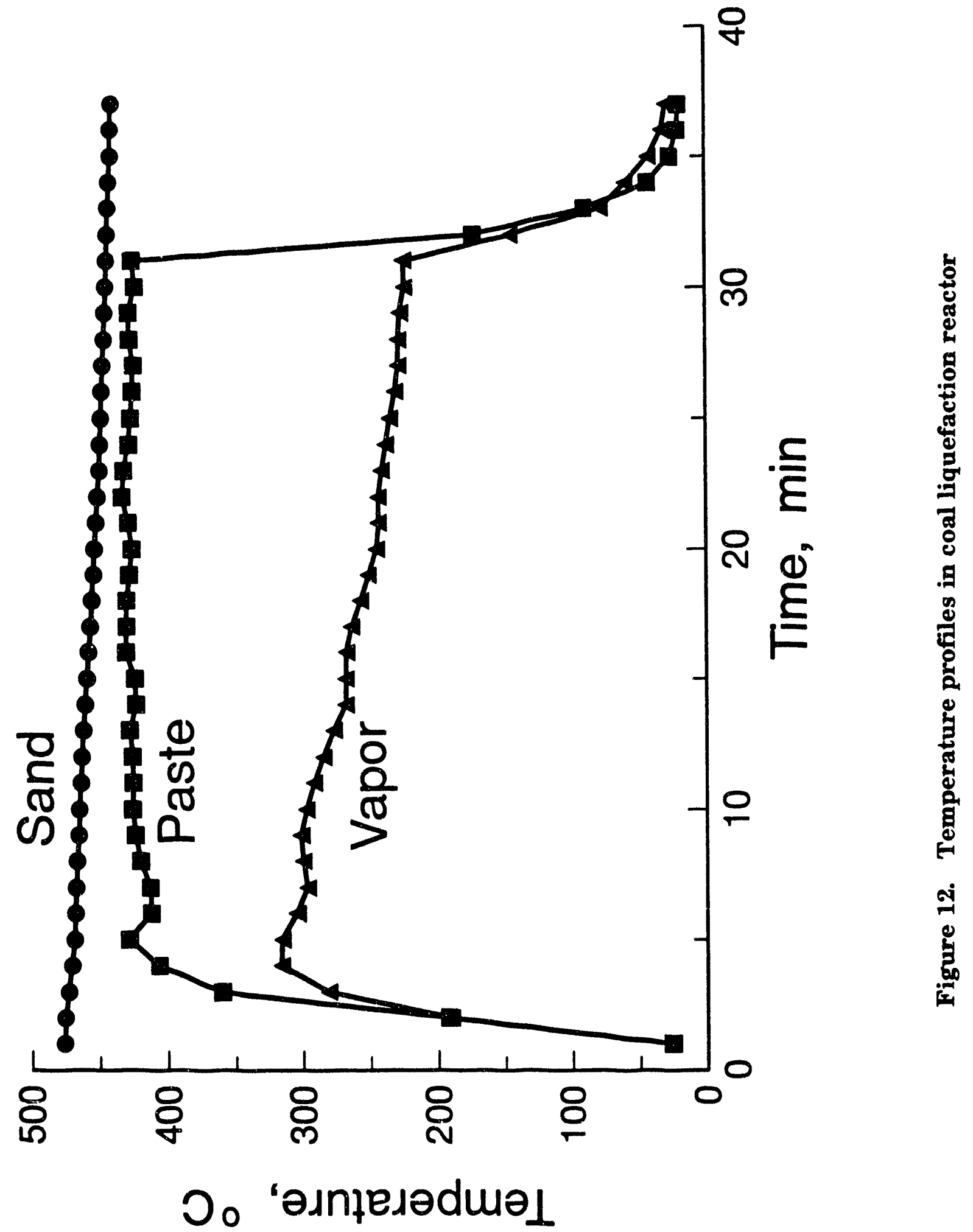




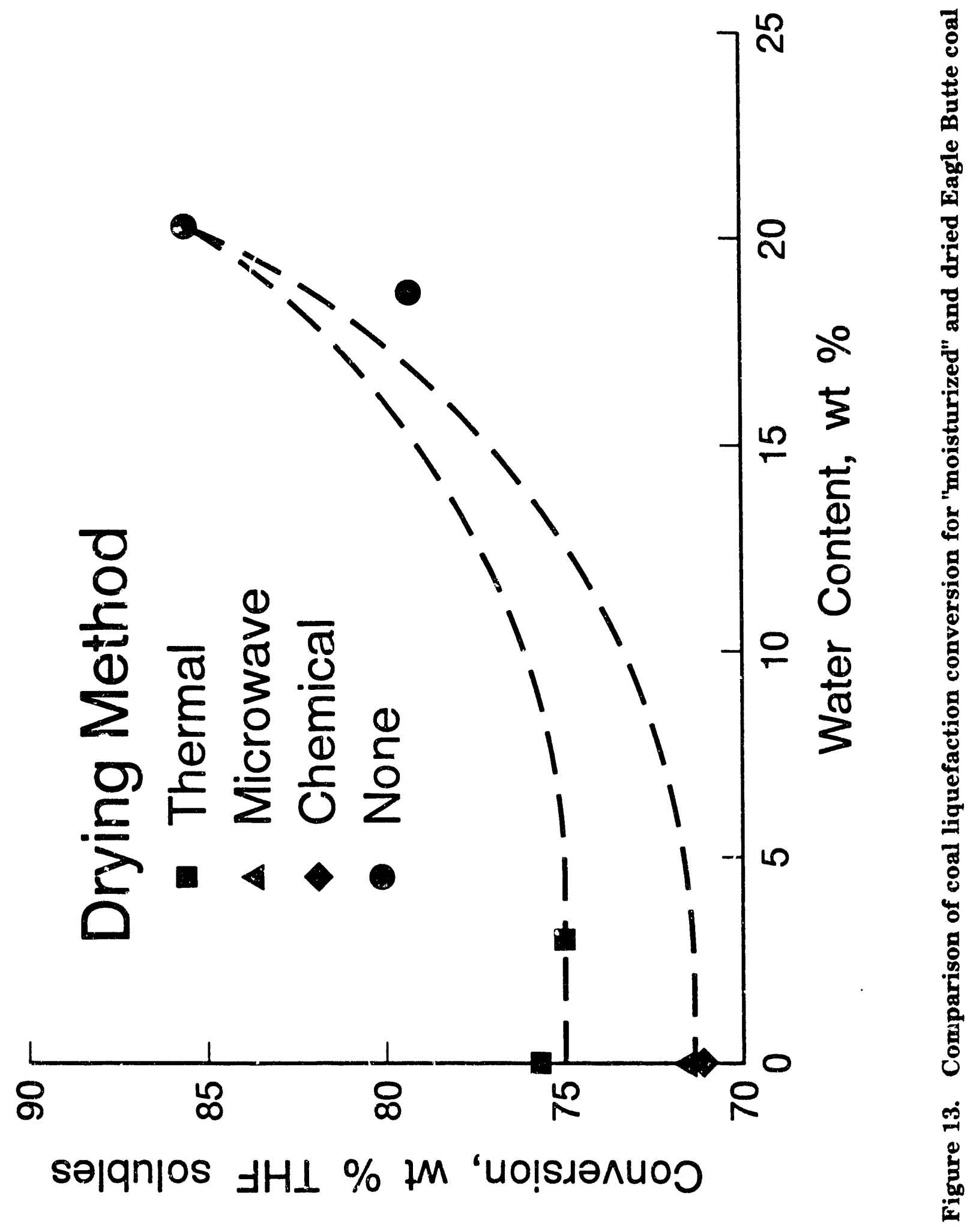




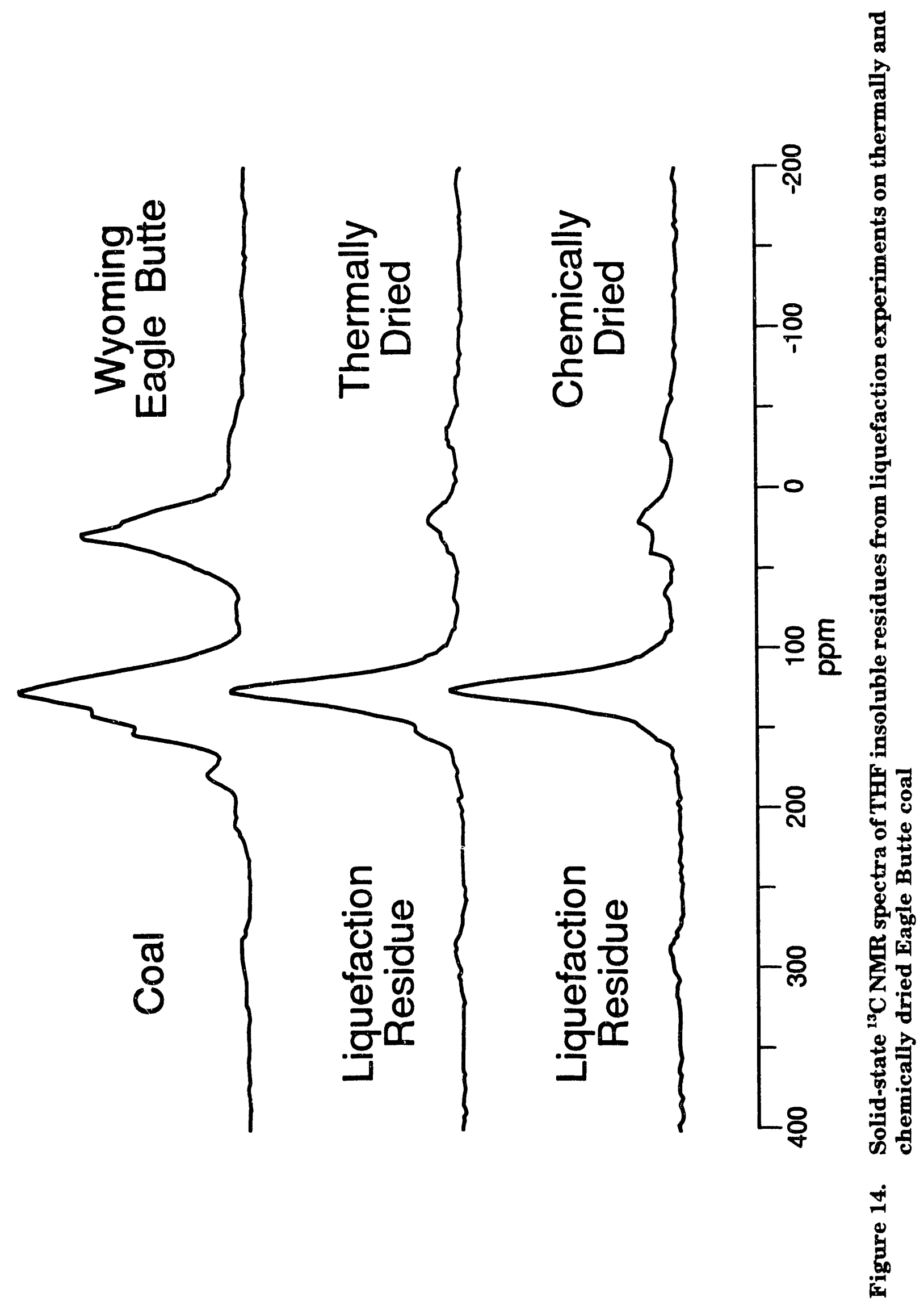



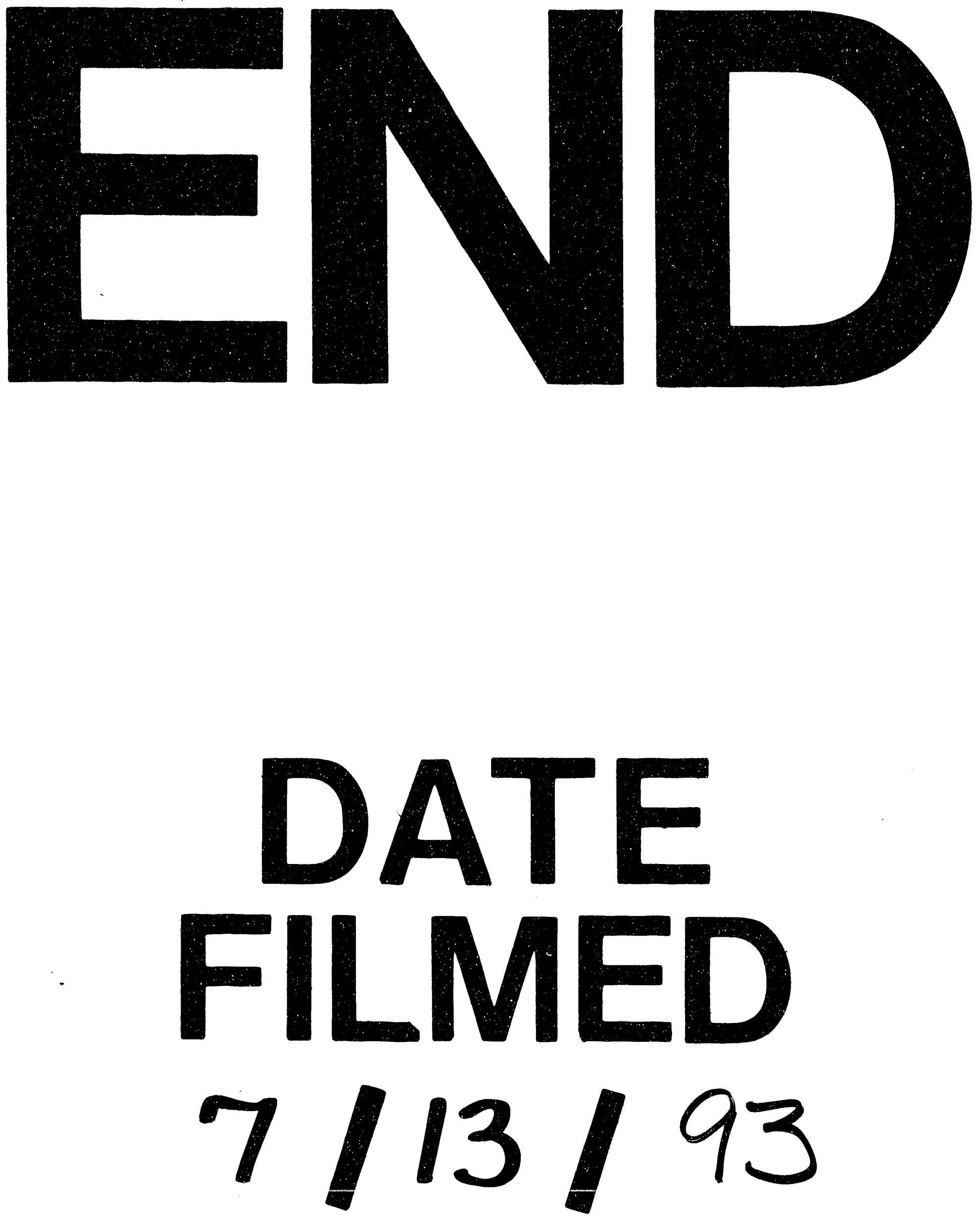
